\title{
Effects of Eurycoma Longifolia Extract on the Isolated Rat Heart
}

\author{
Mokhtar $\mathrm{RH}^{\mathrm{a}}$, Abdullah $\mathrm{N}^{\mathrm{a}}$, Ayob $\mathrm{A}^{\mathrm{b}}$ \\ ${ }^{a}$ Faculty of Medicine and Health Science, Islamic Science University of Malaysia, Kuala Lumpur, Malaysia \\ ${ }^{b}$ Department of Pharmacology (Pathology Division), School of Medicine, International Medical University \\ ABSTRACT
}

Introduction: Eurycoma longifolia (E. longifolia) which is better known locally as Tongkat Ali is an indigenous plant in Malaysia. It belongs to the family of Simaroubaceae and is popular as a traditional medicine for its aphrodisiac properties. Throughout the years, several studies have been conducted to prove its effect on aphrodisiac action, antimalarial, antibacterial and anxiolytic properties but its effect to the cardiovascular system had not been fully explored. This study was aimed to demonstrate the changes that take place in the isolated heart following the injection of the extract. Methods: Three parameters that were measured included the coronary perfusion pressure (CPP), the left ventricular developed pressure (LVDP) and the heart rate (HR). Eighteen isolated rat hearts were used and were divided equally into three groups. The first group was to observe the effect of Isoprenaline, a B agonist while the second group was to see the effect of sodium nitroprusside (SNP), a nitric oxide (NO) donor. The dose which gave the maximum effect for these two positive controls was used to compare with the effect of $E$. longifolia water extract in the third group of rats. Isolated heart was mounted using the Langendorff apparatus and perfused with modified Krebs-Henseleit buffer. Doses of controls and the extract were instilled through an injection port, and the effect of each dose was monitored. Results: E. longifolia extract was found to reduce the CPP in normotensive rat at two of the highest doses. A dose of $1.0 \mathrm{mg}$ of the extract reduced the CPP significantly from $34.52 \pm 4.99 \mathrm{mmHg}$ of the baseline value to $31.99 \pm 4.93 \mathrm{mmHg}$ while the dose of $10.0 \mathrm{mg}$ of the extract reduced the CPP significantly to $32.67 \pm 3.89 \mathrm{mmHg}$. However, there were no significant changes of effect of the extract on the LVDP and HR as compared to control. Conclusion: These early findings suggest that $E$. longifolia extract may have vasodilatory property, which supports its traditional usage with minimum cardiovascular side effects.

KEYWORDS: Eurycoma longifolia, Tongkat Ali, Cardiovascular, Langendorff Technique

\section{INTRODUCTION}

Eurycoma longifolia (E. longifolia) is a herbal plant which is popular in the Malay herbal medicine for its greatly acclaimed aphrodisiac effect. The plant grows wildly in the slopes of the jungle in Malaysia and Indonesia. It has also been widely used as an essential ingredient in Malay herbal medicine for intermittent fever, believed to be for malarial infections. ${ }^{1,2}$ This has led to numerous studies, which revealed that $E$. longifolia possessed properties such as antimalarial effect, ${ }^{3,4,5}$ cytotoxic and anticancer, ${ }^{6,7,8}$ antihyperglycemic, ${ }^{9}$ antibacterial, ${ }^{10}$ and anxiolytic effect. ${ }^{11}$

The traditional indications for fever and aphrodisiac properties have led to the plant being highly developed

\section{Corresponding author:}

Rafidah Hanim Mokhtar, MD, PhD

Faculty of Medicine and Health Science,

Islamic Science University of Malaysia ,

Tingkat 13, Menara B, Persiaran MPAJ

Jalan Pandan Utama, Pandan Indah,

55100 Kuala Lumpur, Malaysia

Tel : 03-4289 2400 Fax : 03-4289 2477

Email address: rafidahhanim@gmail.com,

rafidahhanim@usim.edu.my into more than two hundreds $E$. longifolia preparations by 140 licensed Malaysian manufactures. ${ }^{12}$ Throughout the years, there were various forms of preparations of this herb, especially as dietary supplement in the form of shake, beverages, liquid, gel, tablet, confectionery and supplement food. A topical application containing $E$. longifolia root extract to promote weight loss has also been developed. ${ }^{13}$

Despite its popularity, the direct cardioactivity effect of the plant has never been explored except that which had been caused by contamination of the product. ${ }^{14}$ This possibility needs to be established as some herbals have been associated with adverse cardiac effects driven by altered sympathetic activity, altered platelet function, increase blood pressure and also cardiac arrhythmias. ${ }^{15}$ Apart from the fact that herbal plants may produce a direct side effect, others like ginger, Fenugreek and Gingko biloba causes interactions with another drug like warfarin resulting in an over anticoagulation. ${ }^{16}$

This study aims to evaluate the effect of $E$. longifolia extract on cardioactivity via the isolated rat heart technique. A Langendorff method of non-working heart was employed. The extract effect on heart rate (HR) and left ventricular diastolic pressure (LVDP) was compared against Isoprenaline, a $B$ agonist which acted 
as the positive control, while sodium nitroprusside (SNP) acted as the positive control for the extract effect on coronary perfusion pressure (CPP).

\section{MATERIALS AND METHODS}

\section{Plant material}

The plants of $E$. longifolia were obtained locally from the wild in Raub, Pahang in January 2008. The morphological comparison was done with an authentic sample previously deposited at the herbarium of Forest Research Institute of Malaysia (FRIM) (voucher number MTA 0001). Briefly, the root of the plant was cut and extracted. Water extracts method was used over organic extract as it mimicked the way the plant was boiled traditionally to make decoctions. ${ }^{17}$ The roots were washed with water and dried in a hot air oven for 48 hours at a temperature over $300 \mathrm{C}$. The root flakes were extracted with water by two step process namely the solid-liquid extraction and spray drying ${ }^{18}$ where they were boiled in eight litres of distilled water for 60 minutes at a temperature of $1000 \mathrm{C}$. The water extract was filtered using a Buchner filter to produce the supernatant. The supernatant was concentrated by evaporation under vacuum at $400 \mathrm{C}$ using the rotary evaporator (BÜCHI Rotavapor R-210/ 215, Switzerland) before being fed to the spray drier. The water extract was kept in a close container at a temperature of $40 \mathrm{C}$ before being freeze dried (BÜCHI-191 Mini Spray Drier, Switzerland) at $1600 \mathrm{C}$ at 5 mbar of compressed air. The final product obtained from $1 \mathrm{~kg}$ of $E$. longifolia flakes were 240 grams of powdered $E$. longifolia which gave the yield of $2.4 \%$. The powdered form was kept in a tight container until further usage.

\section{Animals}

The animals care and experimental protocols were approved by the Animal Care Committee of the International Islamic University of Malaysia. Isolated rat hearts were prepared from 18 female normotensive Sprague-Dawley rats, aged between 3 to four months with body weight between 200 to 220 grams. The animals were fed and given water ad libitum.

\section{Isolated heart preparation}

A modified Krebs-Henseleit solution ${ }^{19}$ was prepared and diluted to a total volume of two litres. The solution was prepared fresh daily and kept at a constant $\mathrm{pH}$ of 7.5. Constant flow was maintained by a peristaltic pump. Both the organ bath and the perfusate were kept at a constant temperature of $37^{\circ} \mathrm{C}$.

The animals were anaesthetized by injecting $0.6 \mathrm{mg} / \mathrm{kg}$ of sodium pentobarbital intraperitoneally. Anaesthesia effect was confirmed by the absence of pedal and tail reflexes. The rat was injected intravenously with 0.5 $\mathrm{ml}$ of sodium heparin to prevent blood coagulation and formation of thrombi. After 10 minutes, a transabdominal incision was made to access the diaphragm. The heart was quickly excised by cutting it at the level of the thoracic aorta. It was placed in ice-cold KrebsHenseleit solution to increase the cannulation time and reduce the risk of ischemia injury prior to perfusion. ${ }^{20}$
The aorta was quickly located and the first transducer that measured CPP was inserted into the aorta. The end of the transducer was ensured not to go beyond the aortic valve. The aorta was clamped using serafine clamps. A string was tied above the coronary circulation and below the first aortic branch to secure it. Retrograde perfusion was started within 60 to 90 seconds after the heart was removed. During the mounting of the heart, the flow of perfusate was set at $3 \mathrm{ml} / \mathrm{min}$ and increase to $5 \mathrm{ml} / \mathrm{min}$ once the heart was secured. This flow rate was determined according to the animal weight using the formula as used by Ulker et al. ${ }^{21}$ :

Flow $(\mathrm{ml} / \mathrm{min})=\mathrm{z} \times 0.56 \times 7.43 \quad(\mathrm{z}=$ heart weight $)$ Heart weight $(\mathrm{mg})=0.0027 \mathrm{y}+0.6 \quad(\mathrm{y}=$ body weight $)$

After the heart had been adequately perfused, a balloon catheter was inserted via the aortic valve into the left ventricle to allow recording of LVDP and HR. The balloon was secured by tying the hole made at the atrium to prevent herniation. It was then inflated until the end-diastolic pressure (EDP) at the monitors read approximately 4 to seven $\mathrm{mmHg}$. The measurement was made using a one $\mathrm{ml}$ syringe attached to the transducer system and kept constant throughout the experiment. ${ }^{22}$ Insertion was confirmed by the presence of regular contraction wave at the monitor. The heart was left to stabilize for approximately 15 to 20 minutes before the experiment started. ${ }^{23,24}$ Stabilization was confirmed by the presence of a regular reading of the CPP, LVDP and HR. Any isolated heart, which developed arrhythmia during this period was discarded. All drugs were given retrogradely into the perfusion tube through an injection port located at the junction block just above the heart.

\section{Data acquisition}

Transducers were directed to the analog-to-digital converter (PowerLab Data Acquisition, AD Instruments, Australia). All data were digitalized and displayed using Chart5 software and displayed at the monitor using 4 channels; for CPP, flow, LVDP and HR respectively. The present study had chosen to measure the CPP as it was easier to monitor, sensitive to changes in coronary flow $^{20}$ and was directly proportionate to vascular resistance. ${ }^{25}$ The cardiac function was observed through the LVDP to measure the isometric tension developed by the left ventricle (LV) as previously reported. ${ }^{26}$ LVDP was represented by the cyclic height which is the height of one complete waveform or similar to a calculation of left ventricular end systolic pressure (LVESP) minus left ventricular end diastolic pressure (LVEDP). Likewise, the HR was also calculated from the left ventricular pressure using cyclic measurement. The HR was represented by the rate of the peak of waveform cycles.

\section{Drug preparation}

E. longifolia stock solution was prepared fresh daily by diluting one gram of its powdered form to $100 \mathrm{ml}$ saline to make up a stock solution of $10 \mathrm{mg} /$ $\mathrm{ml}$. This stock solution was further diluted to doses of $0.001,0.01,0.1,1.0$ and $10.0 \mathrm{mg}$ in one $\mathrm{ml}$ saline. 
Isoproterenol hydrochloride (Isoprenaline) (molecular weight: $250 \mathrm{gram} / \mathrm{mol}$ ), was used as a positive control. Isoprenaline at 0.25 gram was diluted to produce $10,000 \mathrm{nmol} / \mathrm{ml}$ of stock solution, prepared fresh daily. It was then diluted accordingly to produce the following doses: $0.1,1.0,10.0,100.0$ and $1000.0 \mathrm{nmol}$ in $1 \mathrm{ml}$ saline.24 SNP (molecular weight: $300 \mathrm{gram} /$ $\mathrm{mol}$ ) at 0.3 grams were diluted in saline solution to produce $10 \mu \mathrm{mol}$ per $\mathrm{ml}$ of stock solution. It was then diluted to the following doses: $0.0001,0.001,0.01$, 0.1 and $1.0 \mu \mathrm{mol}$ in one $\mathrm{ml}$ saline. ${ }^{23}$

\section{Protocol of experiment}

The animals were divided into three groups where each group consisted of six rats. Before the administration of drugs and extract, the baseline parameters were sampled for a 5-minute period following the equilibration phase. The same heart was used both for control preparation and evaluation of the effects of the drugs or extracts. ${ }^{27,28}$ Group 1 received one $\mathrm{ml}$ of Isoprenaline, which was administered to the isolated heart rats in a dose increasing manner from $0.1 \mathrm{nmol}$ to $1000 \mathrm{nmol}$. Observation was taken over the period of 5 minutes, and the effect of each dose of drug was terminated by washing it with three $\mathrm{ml}$ of Krebs Henseleit solution. The next dose was given only after the parameters return to baseline value.

Group 2 involved the administration of SNP also in a dose increasing manner. The protocol was similar to Isoprenaline. In these first two groups, the dose which gave the maximum and consistent response to the CPP, LVDP and HR were taken as the positive control does to be used against the E. longifolia extract.

Group 3 consisted of administration of the $E$. longifolia extract in increasing dose from 0.001 to $10 \mathrm{mg}$ following similar protocol to the positive controls. After the maximum dose administration, once the value has returned to baseline, the predetermined maximum response dose of isoprenaline was administered followed by that of SNP with an adequate wash period in between. The sampling conditions for obtaining the mean values for the three parameters were taken at 1-minute intervals after drug injection for the period of 5 minutes. This period was considered to eliminate the masking pressure that might develop because of the act of injection at the injection port rather than the actual pressure that developed due to the effect of the drug.

\section{Data Analysis}

All results obtained from the experiments were presented as mean \pm standard deviation. All statistical analyses were performed using SPSS version 13 statistical software package. Normal distribution of data was verified with Kolmogorov-Smirnov test. For isoprenaline and SNP, the effect of each dose was compared to the control value using Student's t-test. The level of significance was determined at $p<0.05$. The mean effect of the $E$. longifolia extracts and the positive controls against the baseline value on the same isolated rat heart were compared using
Student's-t test. One-way analysis of variance (ANOVA) test was used to compare the effects of the different concentration of $\mathrm{E}$. longifolia extract against the positive controls. When a significant effect was detected, the data were further analyzed using multiple comparisons with Fisher's least significant difference (LSD).

\section{RESULTS}

\section{Determination of maximum effective dose of SNP and Isoprenaline}

SNP induced a significant reduction in CPP at the dose range of $0.0001 \mu \mathrm{mol}$ to $1 \mu \mathrm{mol}$. The maximum reduction was seen at the maximum dose of $1.0 \mu \mathrm{mol}$ where it produced a $37 \%$ reduction from baseline value to $24.58 \pm 1.72 \mathrm{mmHg}$. SNP at $1.0 \mu \mathrm{mol}$ was used in this study as a positive control for CPP.

A $100 \mathrm{nmol}$ concentration of Isoprenaline was used as a positive control for evaluation of the E.longifolia extract in terms of LVDP and HR parameters as it produced the maximum increase of $65 \%$ and $50 \%$, from the baseline values of $23.40 \pm 4.99 \mathrm{mmHg}$ and 161.12 \pm 9.67 beats per minute respectively.

\section{Effect of $E$. longifolia extract on coronary perfusion pressure (CPP)}

There was a reduction in CPP at three lowest doses of E.longifolia extract, but they did not reach the statistically significant level. Significant reduction was observed only at the concentration values of 1.0 and $10.0 \mathrm{mg}$ (Figure 1). In the same isolated heart preparation, SNP significantly reduced the CPP to 31.21 $\pm 4.85 \mathrm{mmHg}$. One-way ANOVA comparing the effect of E. longifolia extracts to SNP showed that there was no significant difference in reduction of CPP by both SNP and E. longifolia extract $(\mathrm{p}=0.809)$.

\section{Effect E.longifolia extract On Left Ventricular Developed Pressure (LVDP)}

Table 1 showed that $E$. longifolia extract did not produce any statistically significant changes of the LVDP from the baseline value while Isoprenaline of 100 $\mathrm{nmol}$ in the same isolated heart preparation produced a statistically significant increased of LVDP $(p<0.001)$. One-way ANOVA comparing the $E$. longifolia extract with Isoprenaline showed a statistically significant difference among the various doses of the extracts, and Isoprenaline $(p<0.001)$. Further analyses using multiple comparisons with Fisher's LSD in Table 2 revealed that the mean LVDP showed significant differences between Isoprenaline and the extract doses $(p<0.001)$. However, there were no significant differences between the various doses of the extract to one another. 


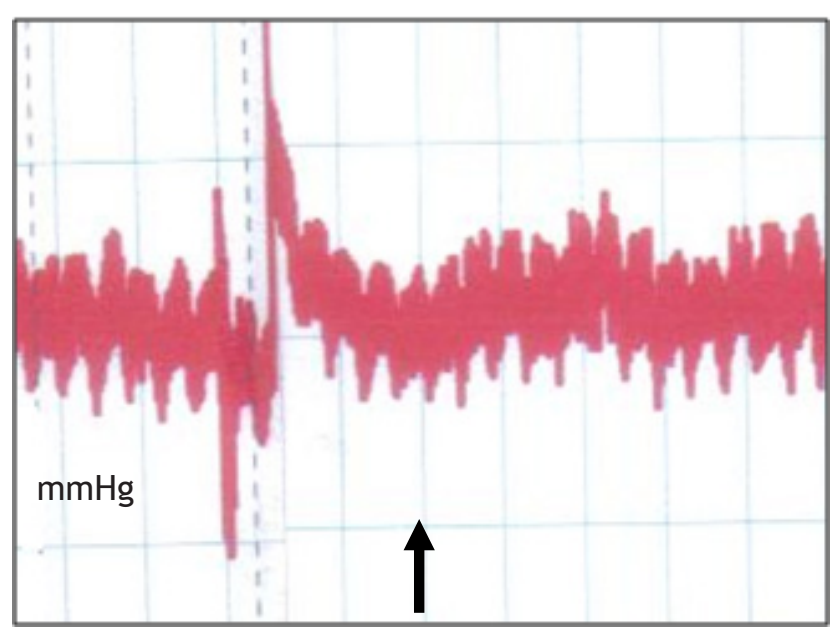

seconds

$0.001 \mathrm{mg}$ E. longifolia

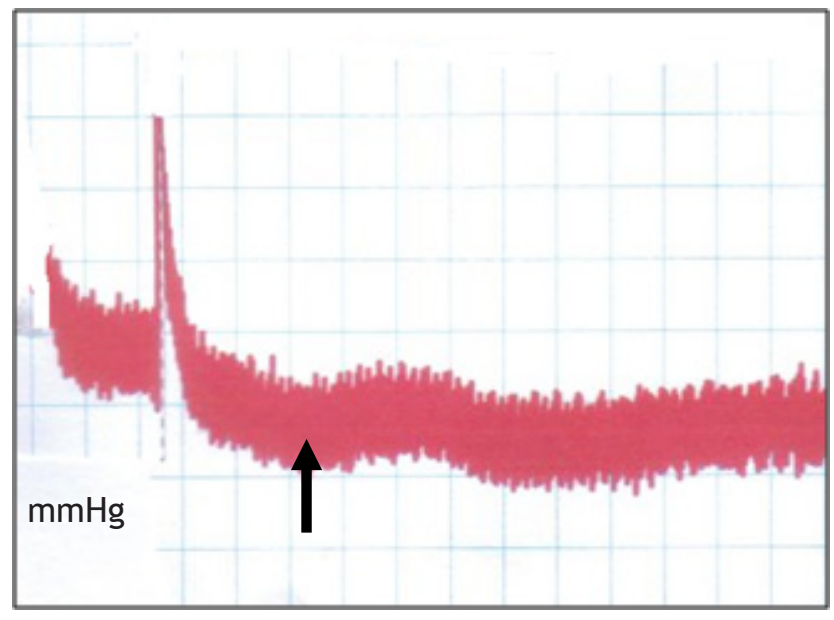

seconds

$0.1 \mathrm{mg}$ E. longifolia

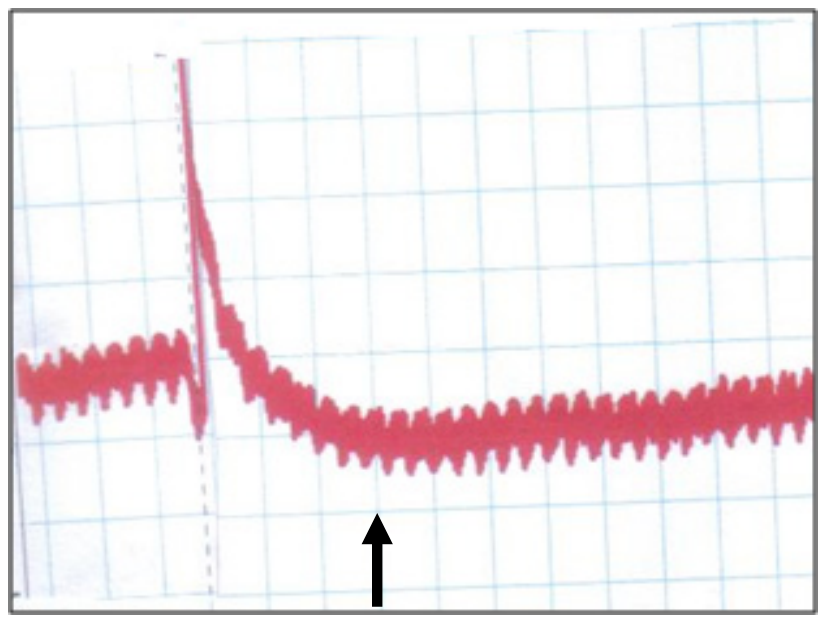

$0.01 \mathrm{mg}$ E. longifolia

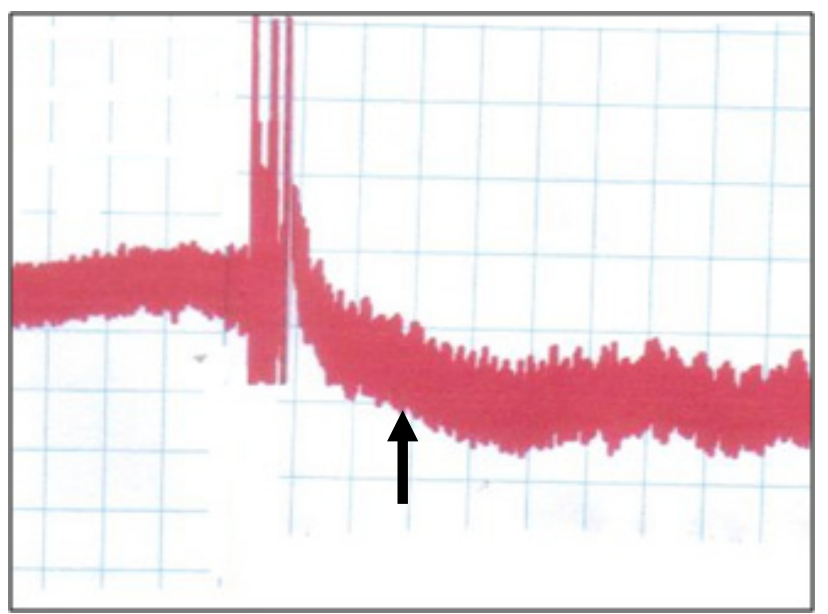

1.0mg E. longifolia

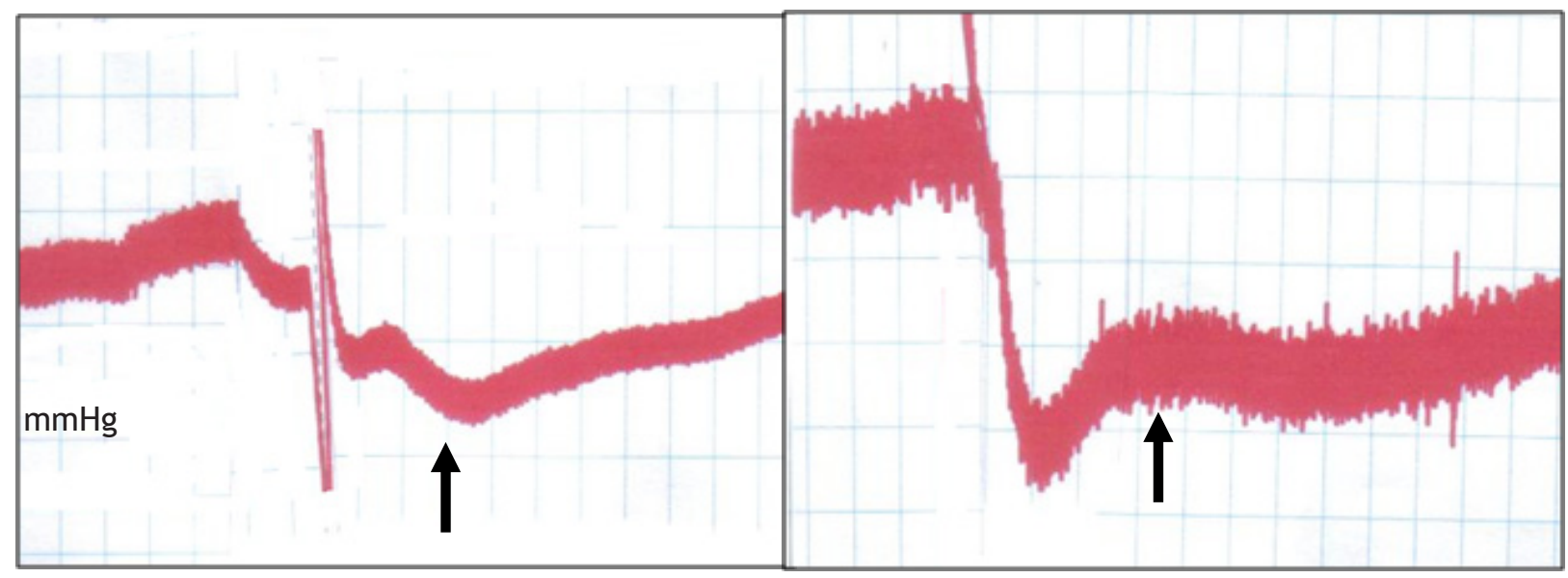

seconds

$10.0 \mathrm{mg}$ E. longifolia

$1.0 \mu \mathrm{mol}$ SNP

Figure 1. Changes in CPP of the isolated heart rat after the administration of various doses of $E$. longifolia as compared to SNP. Note: Arrow shows the time of extract and drug administration. 
Table 1. Effect of various doses of E. longifolia extract and Isoprenaline on LVDP.

\begin{tabular}{llll}
\hline & & $\begin{array}{l}\text { Mean LVDP } \pm \text { SD } \\
(\mathrm{mmHg}) \\
(\mathrm{n}=6)\end{array}$ & p value \\
& & & \\
\hline Baseline & $24.47 \pm 2.28$ & \\
Extract of $E$. & $25.24 \pm 1.55$ & 0.207 \\
longifolia (mg) & 0.001 & $25.58 \pm 1.66$ & 0.059 \\
& 0.01 & $26.89 \pm 3.28$ & 0.087 \\
& 0.1 & $25.99 \pm 1.45$ & 0.095 \\
& 1.0 & $25.84 \pm 2.02$ & 0.079 \\
& 10.0 & $35.78 \pm 3.28$ & $<0.001^{*}$ \\
$\begin{array}{l}\text { Isoprenalinerenaline } \\
\text { (100.0 nmol) }\end{array}$ & & & \\
\hline
\end{tabular}

${ }^{*} \mathrm{p}<0.01$, LVDP: left ventricular developed pressure

Table 2. One-way ANOVA with post hoc LSD comparing the differences of Isoprenaline and E. longifolia extracts on LVDP.

\begin{tabular}{|c|c|c|c|c|}
\hline & $\begin{array}{l}\text { E. longifolia } \\
\text { concentration (mg) } \\
(\mathrm{n}=6)\end{array}$ & $\begin{array}{l}\text { Mean LVDP } \\
\text { difference } \\
\text { (mmHg) }\end{array}$ & $\mathrm{df}(5,30)$ & $p$ value \\
\hline \multicolumn{5}{|l|}{ Isoprenaline } \\
\hline & 0.001 & 10.54 & \multirow{5}{*}{$F=18.06$} & \multirow{5}{*}{$<0.001^{*}$} \\
\hline & 0.01 & 10.20 & & \\
\hline & 0.1 & 8.89 & & \\
\hline & 1.0 & 9.78 & & \\
\hline & 10.0 & 9.94 & & \\
\hline \multicolumn{5}{|l|}{$\begin{array}{l}\text { E. longifolia } \\
\text { concentration (mg) }\end{array}$} \\
\hline \multicolumn{5}{|l|}{0.001} \\
\hline \multicolumn{5}{|l|}{0.01} \\
\hline 0.1 & \multirow{2}{*}{\multicolumn{2}{|c|}{$\begin{array}{l}\text { Against all } \\
\text { concentrations } \\
\text { of E. Longifolia }\end{array}$}} & $F=2.53$ & \multirow[t]{2}{*}{ NS } \\
\hline 1.0 & & & & \\
\hline 10.0 & & & & \\
\hline
\end{tabular}

NS: non significant, LVDP:left ventricular developed pressure 
Effect of E.longifolia extract On Heart Rate (HR)

Table 3 showed that following the administration of $E$. longifolia extract, there was no significant difference in changes of HR. On the other hand, Isoprenaline on the same isolated heart produced a significant positive chronotropic effect $(p<0.001)$. One-way ANOVA revealed statistically significant difference existed among the Isoprenaline, and the various doses of the E. longifolia extract and the LSD post hoc test revealed that the mean HR showed significant differences between Isoprenaline with each dose of the extract (Table 4). However, there were no significance differences of mean HR between the different E. longifolia extract dosages.

Table 3. Effect of various doses of E. longifolia extracts and Isoprenaline on HR.

\begin{tabular}{llll}
\hline & & $\begin{array}{l}\text { Mean LVDP } \pm \text { SD } \\
(\mathrm{mmHg}) \\
(\mathrm{n}=6)\end{array}$ & p value \\
\hline Baseline & $278.23 \pm 12.42$ & \\
$\begin{array}{l}\text { Extract of } E . \\
\text { longifolia }(\mathrm{mg})\end{array}$ & 0.001 & $278.95 \pm 15.24$ & 0.892 \\
& 0.01 & $286.23 \pm 19.10$ & 0.510 \\
& 0.1 & $286.85 \pm 17.63$ & 0.450 \\
& 1.0 & $285.23 \pm 26.27$ & 0.615 \\
& 10.0 & $288.68 \pm 23.19$ & 0.376 \\
$\begin{array}{l}\text { Isoprenalinerenaline } \\
(100.0 \text { nmol) }\end{array}$ & & $343.60 \pm 21.75$ & $<0.001^{*}$ \\
\hline
\end{tabular}

${ }^{*} \mathrm{p}<0.01, \mathrm{HR}=$ heart rate

Table 4. One-way ANOVA with post hoc LSD comparing the differences of Isoprenaline and E. longifolia extracts on HR.

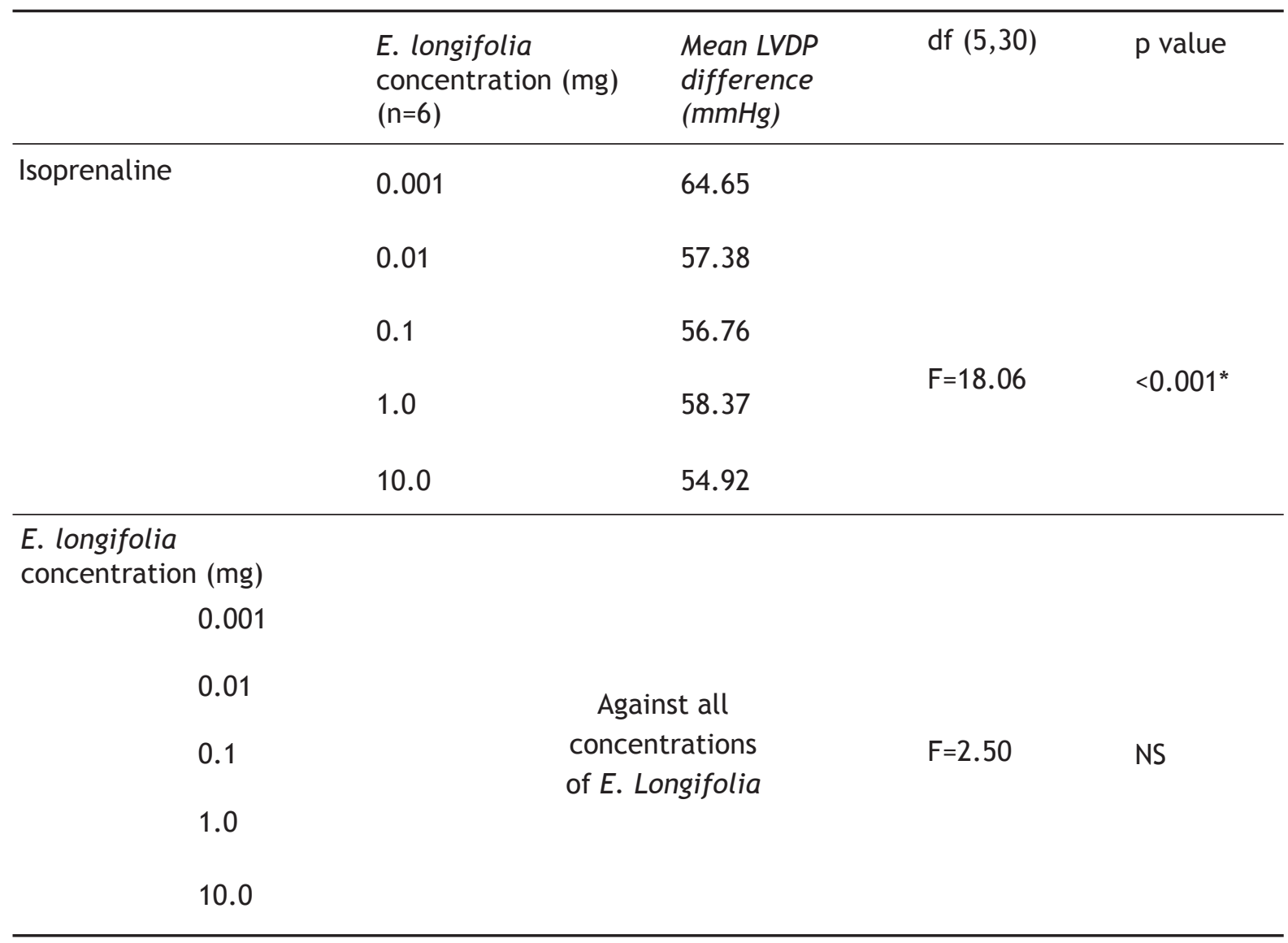

${ }^{*} \mathrm{p}<0.01, \mathrm{HR}=$ heart rate 


\section{DISCUSSION}

The main findings observed with the extract were: 1 ) There was statistically significant reduction of CPP at the dose of $1.0 \mathrm{mg}$ and $10.0 \mathrm{mg}$ of $\mathrm{E}$. longifolia extract compared to baseline: 2 ) The reduction of CPP observed with $1.0 \mathrm{mg}$ and $10.0 \mathrm{mg}$ of $\mathrm{E}$. longifolia extract was not statistically different from the reduction caused by SNP of $1.0 \mu \mathrm{mol}: 3)$ There were no significant changes caused by the extract on either LVDP or HR compared to baseline and : 4) The effect of E. longifolia extracts on LVDP, and HR was significantly different to those seen with Isoprenaline.

It was observed in the present study that Isoprenaline reduced the CPP which resulted from the vasodilatation of the coronary arteries. This is consistent with the known effect of the drug on the vessels through the action on both $B 1$ and $B 2$ adrenoceptors. ${ }^{29}$ Isoprenaline induces vascular smooth muscle (VSM) relaxation through the release of NO from the endothelium and subsequently activating the cyclic guanosine monophosphate at the VSM. ${ }^{30}$ The fact that CPP reduction by $E$. longifolia was not significantly different to those induced by SNP alone may suggest that the vasodilatation was not dose dependent. It could be postulated that $E$. longifolia extract may stimulate the endothelium to produce NO. It also supports earlier observation ${ }^{31}$ which stated that nearly all stimuli which produce vasodilatation through the action of NO. This may suggest that $E$. longifolia extract may bind to an endothelial receptor. On the other hand, the effect of the extract could also be postulated to be nonreceptor mediated. This is through the ability of the extract to inhibit the depolarization of the membrane and interfere with the availability of the $\mathrm{Ca} 2+$ for the contractile process. ${ }^{32}$

The significant effect of the extract can be attributed to the presence of testosterone. It was found that E.longifolia extract significantly increase the amount of testosterone and progesterone, which are produced by rat testicular cell homogenate. ${ }^{33}$ In the same study it was also suggested that the extract helps in vitro preparation to activate enzymes, which convert pregnenolone into progesterone and convert $17-\mathrm{OH}$ pregnenolone into dehydropiandrosterone and subsequently into testosterone. Testosterone was found clinically to reduce the incidence of myocardial ischemia in patients with angina inducing coronary artery dilatation and improving coronary blood flow. ${ }^{34,35}$ This hormone also produced relaxation of the subcutaneous resistant arteries in healthy controls, patients with heart failure and men with androgen deficiency. ${ }^{36}$

It was also observed that $\mathrm{E}$. longifolia given at the dose of $0.001 \mathrm{mg}$ to $10.0 \mathrm{mg}$ did not produce any significant changes to the LVDP and HR. Constant LVDP may safely reduce the possibility of the isolated heart to develop into failure while an increase in it reflects the loss of compliance due to the increase in the diastolic chamber stiffness or contracture. ${ }^{37,38}$ The fact that no changes in LVDP accompanying a stable HR may favourably suggest that the E. longifolia extract did not produce arrhythmia or sinus bradycardia, which would indicate ischemic changes. ${ }^{39}$

The fact that E. longifolia extract did not produce any significant changes to the LVDP and HR may indicate the absence of cardioactive or cardiosuppression agents in the extract. This also supports the earlier findings of reduce CPP, which is very much likely through the direct action on the VSM and not due to cardio suppression. The normal HR without bradycardia also suggests that the vasorelaxant effect may exclude the role of muscarinic receptors.

However, a caution on the seemingly cardioprotective nature of $E$. longifolia extract should be applied by taking into account of the earlier argument of the possible relations of $E$. longifolia extract with testosterone. Testosterone could stimulate myocytes that contain androgen receptor and produce response that lead to structurally, heart muscle hypertrophy. ${ }^{40}$ Androgen receptors, although were also found in female rats, ${ }^{40,}{ }^{41}$ may be present in relatively lower levels of testosterone as compared to male to induce significant structural changes. The endogenous testosterone in male rat can induce a maximum increased in the number of androgen receptor. ${ }^{40}$ Therefore, the fact that there was no significant response in LVDP and HR in this study, which employed female rats may be attributed to this, where the number of androgen receptor present at the isolated heart could be insufficient to form receptor-effectors' complex and produced a significant response. Further study to address the gender influence on E. longifolia extract induced cardiac hypertrophy is needed. Another possible explanation was that the time of exposure of the extract on the isolated heart which determined the testosterone treatment time. Study had shown that shorter treatment time of myocyte with testosterone of approximately 5 minutes had no effect on the contraction and relaxation properties, and the effect was only seen after 24-hours exposure of the myocyte to testosterone. ${ }^{41}$

\section{CONCLUSION}

The findings in this study were consistent with the preliminary study done earlier ${ }^{17}$ that stated the aqueous extract which was injected intravenously resulted in the reduction of blood pressure in normotensive rats. At the same time, the heart rates of the rats were not affected. The present study findings of reduce CPP without significantly affecting LVDP and HR may suggest that the earlier findings of reduction in blood pressure was due to vasodilatation rather than cardio-depressive. It may also be the basis of its traditional usage as reported by Bedir et al. ${ }^{42}$ where the decoction of the roots and root bark was used to treat hypertension. 
This study has explored the non- aphrodisiac property of $E$. longifolia extract namely the cardiovascular effects. Along with its usage in the traditional treatment, the results of this study are among the first work of safely evaluations that suggested any untoward cardiovascular side effects are very unlikely. The result may give a promising approach toward the development of this medicinal plant as a cardiac drug while at the same time able to give assurance on the safety of consuming it.

\section{Acknowledgement}

The authors would like to thank the International Islamic University of Malaysia for the research grant provided (IIUM/504/RES/G/14/3/01/LT43). We would also like to thank Miss Nur Hayati Bujang, Mr Zulnizam Azdan, Miss Anirawati M. Sahir, Miss Norsyafawati A. Zabidi, Mr M. Shahriman Ghazali and Mr M. Fadhlilullah M. Yusuf for their technical assistance.

Disclosure statement: No conflict to disclose.

\section{REFERENCES}

1. Gimlette JD, Thomson HW, eds. A dictionary of Malayan medicine. Kuala Lumpur: Oxford University Press, 1977.

2. Perry LM, Metzger J, eds. Medicinal plants of East and Southeast Asia: Attributed properties and uses. Massachusetts: Massachusetts Institute of Technology Press, 1980.

3. Kardono LBS, Angerhofer CK, Tsauri S, et al. Cytotoxic and antimalarial constituents of the roots of Eurycoma longifolia. J Nat Prod 1991; 5:1360-7.

4. Ang HH, Chan KL, Mak JW. Effect of 7-day daily replacement of culture medium containing Eurycoma longifolia jack constituents on the Malaysian Plasmodium falciparum isolates. $\mathrm{J}$ Ethnopharmacol 1995; 49:171-5.

5. Mohd Ridzuan MA, Sow A, Noor Rain A, Mohd Ilham A, Zakiah I. Eurycoma longifolia extract-artemisinin combination: parasitemia suppression of Plasmodium yoelli-infected mice. Trop Biomed 2007; 24:111-8.

6. Ueda JY, Tezuka Y, Banskota AH, et al. Antiproliferative activity of Vietnamese Medicinal Plants. Biol Pharm Bull 2002; 25:753-60.

7. Tee TT, Azimahtol HLP. Induction of apoptosis by Eurycoma longifolia jack extract. Anticancer Res 2005; 25:2205-13.

8. Tee, TT, Cheah YH, Azimahtol HLP. F16, a fraction from Eurycoma lonfigolia jack extract, induces apoptosis via a caspase-9-independent manner in MCF-7 cells. Anticancer Res 2007; 27:3425-30.

9. RafidAh H, Azimahtol HLP, Nallappan M. Screening for antihyperglycaemic activity in several local herbs of Malaysia. J Ethnopharmacol 2004; 95: 205-8.

10. Farouk AE, Benafri A. Antibacterial activity of Eurycoma longifolia Jack. A Malaysian medicinal plant. Saudi Med J 2007; 28:1422-4.
11. Ang HH, Cheang HS. Studies on the anxiolytic activity of Eurycoma longifolia Jack roots in mice. Jpn J Pharmacol 1999; 7:497-500.

12. Ang $\mathrm{HH}$. An insight into Malaysian herbal medicine. Trends Pharmacol Sci 2004; 25:297-8.

13. Talbott SM. Weight loss compositions using citrus peel extract and Eurycoma longifolia. U.S. Patent Application 11/690,754, filed March 23, 2007. (U.S. Patent 20070224300).

14. Ang $\mathrm{HH}$, Lee KL. Analysis of mercury in Malaysian herbal preparation. Journal of Medicine and Biomedical Research 2005; 4:31-36.

15. Yilmaz MB, Yontar OC, Turgut OO, et al. Herbs in cardiovascular practice: Are physicians neglecting anything? Int J Cardiol 2007; 12:48-51.

16. Izzo AA, Di Carlo G, Borrelli F, Ernst E. Cardiovascular pharmacotheraphy and herbal medicines: the risk of drug interaction. Int J Cardiol 2005; 98:1-14.

17. Ng LT, Anderson HG. Effect of aqueous extract of Eurycoma longifolia on blood pressure in rats. International Union of Pure and Applied Chemistry 1997. Available at: http://www. fao.org/agris/display.do?f=./2006/TH/TH0504. xml;TH2002001122. Accessed Jun 7, 2008.

18. Kuan CK, Foo DCY, Tan RR, Kumaresan S, Ramlan AA. Streamlined life cycle assessment of residue utilization options in Tongkat Ali (Eurycoma longifolia) water extract manufacturing process. Clean Technol Envir 2007; 9:287-301.

19. Suntherland F, Hearse D. The isolated blood and perfusion fluid perfused heart. Pharmacol Res 2000; 41:613-27.

20. Skrzypiec-Spring M, Grotthus B, Szelag A, Schulz R. Isolated heart perfusion according to Langendorff-still viable in the new millennium. J Pharmacol Toxicol Methods 2007; 55:113-126.

21. Ulker S, Mckeown PP, Bayraktutan U. Aprotinin impairs coronary endothelial function and downregulates endothelial NOS in rat coronary microvascular endothelial cells. Cardiovasc Res 2002; 55:830-7.

23. Ridzwan BH, Fong YS, Hasniwati MH, Shaari B, Jalal KCA. The effect of Morinda citrofilia on isolated rat hearts. Pak J Biol Sci 2002; 5:1095-7.

24. Tan WT, Fong YS, Ridzwan BH. The effect of coelomic fluid Stichopus hermanii on isolated perfused rat hearts and the involvement of prostaglandin in its mechanism of action. Pak J Biol Sci 2005; 8:78-84.

25. Spaan AE, Piek JJ, Siebes M. Coronary circulation and hemodynamics. In: Kurachi Y, Terzic A, Cohen M, Sperelakis N, eds. Heart physiology and pathophysiology. Amsterdam: Academic Press, 2001.

26. Ahmad F. The Langendorff heart. In: McNeill JH, ed. Measurement of cardiac function. United Kingdom: Informa Health Care, 1996: 1-10.

27. Silva RM, Oliveira FA, Cunha KM, et al. Cardiovascular effects of trans-dehydrocrotonin, a diterpene from Croton cajucara in rats. Vasc 
Pharmacol 2005; 43:11-8.

28. Mukaddam-Daher S, Menaouar A, Gutkowska J. Receptors involved in monoxidine-stimulated atrial natriuretic peptide release from isolated normotensive rat hearts. Eur J Pharmacol 2006; 541:73-9.

29. Abdelrahman A, Tabrizchi R, Pang CC. Effects of beta 1 and beta2 adrenoreceptor stimulation on hemodynamics in the anesthetized rat. J Cardiovasc Pharmacol 1990; 15:720-8.

30. Klabunde RE. Cardiovascular physiology concept. 1st ed. Philadelphia: Lippincott Williams and Wilkins, 2004.

31. Esper RJ, Nordaby RA, Vilarino JO, et al. Endothelial dysfunction: a comprehensive appraial. Cardiovascular Diabetology. 2006; 5:4. Available at: http :// www. cardiab. com/ content/5/1/4. Accessed January, 2008.

32. Oriee NN. Direct vascular effects of plantain extract in rats. Exp Physiol 1997; 82:501-6.

33. Eng A. Correcting systemic androgen levels using Eurycoma longifolia. U.S. Patent Application 11/176,464, filed July 7, 2005. 2007 U.S. patent 20070009621.

34. Webb CM, McNeill JG, Hayward CS, Zeigler D. Effect of testosterone on coronary vasomotor regulation in with coronary heart disease. Circulation 1999; 100:1690-6.

35. Pugh PJ, Jones RD, Jones TH, Channer KS. Intrinsic response of rat coronary arteries in vitro. Endocrine 2002; 19:155-61.

36. Malkin CJ, Jones RD, Jones TH, Channer KS. Effect of testosterone on ex vivo vascular reactivity in man. Clin Sci 2006; 111:265-74.

37. Friedrichs GS, Kilgore KS, Manley PJ, Gralinski $M R$, Lucchesi BR. Effects of heparin and $\mathrm{N}$-acetyl heparin on ischemia/reperfusion-induced alterations in myocardial function in the rabbit isolated heart. Circ Res 1994; 75:701-10.

38. Nassirah K, Joelle PA, Antoine B. Comparative effects of carvedilol and metaprolol on cardiac ischemia-reperfusion injury. J Cardiovasc Pharmacol 1998; 32:443-51.

39. Pieroni M, Corti A, Tota B, et al. Myocardial production of chromogranin $A$ in human heart: a new regulatory peptide of cardiac function. Eur Heart J 2007; 28:1117-27.

40. Marsh JD, Lehmann MH, Ritchie RH, et al. Androgen receptors mediate hypertrophy in cardiac myocytes. Circulation 1998; 98:256-61.

41. Golden KL, Marsh JD, Jiang Y. Testosterone regulated mRNA leves of calcium regulatory proteins in cardiac myocytes. Hormone Metabolic Research 2004; 36:197-202.

42. Bedir E, Abou-Gazar H, Ngwendson JN, Ikhlas AK. Eurycomaoside:a new quassinoid-type glycoside from the roots of Eurycoma longifolia. Chem Pharml Bull 2003; 51:1301-3. 
